\title{
Association Between Socioeconomic Status and Severity of Oral Epithelial Dysplasia Using a Taiwanese Nationwide Oral Mucosal Screening Program: A Retrospective Analysis
}

\author{
Tien-En Chiang \\ National Defense Medical Center \\ Yu-Chun Lin \\ Tri-Service General Hospital \\ Chi-Tsung Wu \\ National Defense Medical Center \\ Sheng-Tang Wu \\ National Defense Medical Center \\ Yuan-Wu Chen ( $\nabla$ yuanwu789@gmail.com ) \\ National Defense Medical Center
}

\section{Research Article}

Keywords: Oral Epithelial Dysplasia, Oral Potentially Malignant Disorders, Taiwanese Nationwide Oral Mucosal Screening Program, Socioeconomic Status

Posted Date: November 9th, 2021

DOI: https://doi.org/10.21203/rs.3.rs-1016302/v1

License: (c) (i) This work is licensed under a Creative Commons Attribution 4.0 International License.

Read Full License

Version of Record: A version of this preprint was published at BMC Oral Health on March 4th, 2022. See the published version at https://doi.org/10.1186/s12903-022-02084-7. 


\section{Abstract}

Background: The study aimed to investigate the association between socioeconomic status and severity of oral epithelial dysplasia (OED) using current data from the Taiwanese Nationwide Oral Mucosal Screening Program (TNOMSP).

Methods: This retrospective analysis was conducted in the Department of Oral and Maxillofacial Surgery at a general hospital in Taipei, Taiwan. A total of 134 participants were analysed from a previous study database of 150 patients. The inclusion criteria included age over 20 years and a history of either tobacco or betel nut use. Background information, including para-habits such as betel and tobacco use, was analysed using Pearson chi-square $\left(\chi^{2}\right)$ test, furthermore, the correlation of background information with OED severity was investigated using logistic regression (mild or moderate/high).

Results: High school education level $(P<0.001)$, poor self-awareness $(P=0.002)$, current betel use $(P<0.001)$, and tobacco use $(P=0.003)$ were highly correlated with moderate- and high-grade OED $(P<0.05)$. The odds ratio (OR) of education status above senior high school was 0.03 ( $95 \%$ confidence interval $[\mathrm{CI}]: 0.01-0.15, P<0.001)$, while that of junior high school was 1 . Current betel chewing $(\mathrm{OR}=6.57$ [95\% Cl: 1.17-37.0], $P=0.033)$ was significantly associated with OED severity compared with never or exuse of betel.

Conclusions: We found a strong correlation between the severity of OED and current betel use and low education status. The current study revealed the socioeconomic status, poor self-awareness, and parahabits history of the patients with OED should be evaluated to identify high-risk individuals using TNOMSP.

\section{Background}

Histopathological grading of oral epithelial dysplasia (OED) has a predictive value for the malignant potential of oral mucosal lesions [1]. The proportion of OED associated with malignant transformation is approximately $2.2-38.1 \%[2,3]$. The malignant transformation of oral mucosal lesions may manifest in different histopathological stages, early hyperkeratosis or hyperplasia, and various degrees of dysplasia, which are categorised as mild, moderate, and high grade according to the severity of cell atypia and epithelial involvement [4]. Therefore, the precision of conventional oral examination (COE) and early diagnosis of OED is crucial for preventing malignant transformation [5].

COE for oral mucosa screening aims to reduce mortality in malignancy and guide preventive interventions for malignant dysplasia [6]; thus, the definitive diagnosis is crucial. Warnakulasuriya et al. proposed the term oral potentially malignant disorders (OPMDs) to refer to a group of conditions, including leucoplakia, erythroplakia, submucosal fibrosis, palatal lesions in reverse smokers, oral lichen planus, oral lichenoid reactions, and other disorders involving systemic disease or hereditary conditions, which constitute a family of morphological alterations with the potential for malignant transformation $[7,8]$. 
The major risk factors for OED in patients with OPMDs vary across geographical regions. In Southeast Asia, two well-established risk factors are recognised: betel quid chewing and tobacco smoking $[9,10]$. In Taiwan, tobacco smoking and betel quid chewing have been shown to increase the risk of leucoplakia and malignant transformation of OED $[11,12]$. Nevertheless, the socioeconomic status may affect the development of OPMDs or knowledge of mucosal lesions and major risk factors [13]. Therefore, an effective screening programme in the high-risk group has been investigated in several countries [14].

COE is a relatively easy procedure that is used to identify oral lesions [15]. The Taiwanese government has supported oral screening programs for many years [16], and the Taiwanese Nationwide Oral Mucosal Screening Program (TNOMSP) is principally developed and documented in a specific survey [17]. This survey gathers specific background information and para-habits of high-risk individuals. However, a more conclusive diagnosis by a specialist and pathologist is required to confirm and document the OED stage, and a follow-up system for recall and monitoring in high-risk individuals with high-grade OED should be arranged for effective treatment [18]. In this retrospective study, we analysed a group of participants documented in the TNOMSP and investigated the association between the socioeconomic status and severity of OED.

\section{Methods}

A retrospective analysis was conducted in the Department of Oral and Maxillofacial Surgery at a general hospital in Taipei, Taiwan to investigate the association between the socioeconomic status and severity of OED using current data from the TNOMSP.

\section{Study participants}

A total of 134 participants were analysed from a previous study database of 150 patients; 10 patients were excluded due to refusal to participate, and 6 patients were excluded as the study design was limited to Han Chinese only. The study was conducted in the Department of Oral and Maxillofacial Surgery at the Tri-service General Hospital (TSGH) of National Defense Medical Center (NDMC), Taipei, Taiwan. The inclusion criteria were age over 20 years and a history of either tobacco or betel nut use. The study was approved by the institutional review board of TSGH (1-107-05-010).

\section{Patient and public involvement}

As this was a pseudo-anonymised secondary data study, there was no direct patient or public involvement.

\section{Clinical examination procedure and TNOMSP}

The participants were recruited from a previous study involving TNOMSP, which was developed by the Health Promotion Administration of the Ministry of Health and Welfare and is commonly used for oral cancer and OPMD screening in Taiwan. The TNOMSP collects the following background information: name, sex, contact information, age, race, inhabited area, education, history of betel nut and tobacco use, 
and self-awareness. The personally identifiable information, such as name and contact information, was substituted with numbers. A clinical diagnosis of OPMD was obtained from a certified clinical practitioner (Fig. 1), who also recorded the lesion sites. The OPMDs evaluated in the TNOMSP included nonhomogenous leucoplakia, homogenous thick leucoplakia, homogenous thick leucoplakia, leucoplakia, erythroplakia, erythroleucoplakia, verrucous hyperplasia, submucosal fibrosis, lichen planus, and suspected oral cancer. Oral lesion biopsy was performed by a clinical practitioner followed by a pathological diagnosis as mild-, moderate-, or high-grade dysplasia or oral cancer. Finally, various clinical decisions were made according to the provided guidelines (Fig. 2).

\section{Histopathological data}

The study participants agreed to participate and signed a standard informed consent form prior to biopsy performed at TSGH. Each sample biopsy underwent histopathological examination by a pathologist. The presence or absence of dysplasia or oral cancer in the biopsy specimen was recorded in a report from the pathology department at TSGH and approved by a certified pathologist.

\section{Statistical analysis}

All statistical analyses were performed using SPSS version 22.0.0. (IBM Corp., Armonk, NY, USA). The responses were coded as numeric to facilitate data entry. The results were analysed using the Pearson chi-square (X2) test, and odds ratios (ORs) and 95\% confidence intervals ( $95 \% \mathrm{Cls}$ ) were computed to determine any association between the participants' characteristics and OED, with the level of significance set as two-tailed $P<0.05$.

\section{Results}

\section{Participants' demographics}

A total of 134 participants out of 150 individuals in the original TNOMSP were enrolled in the present study (Table 1). After excluding participants with histologically diagnosed oral cancer $(n=6), 112$ males and 16 females $(n=128)$ remained. Regarding the education status, 100 participants $(78.1 \%)$ reached senior high school level or above. The number of participants residing in the capital (Taipei) and noncapital (Majority of New Taipei city surrounding Taipei city) areas were evenly distributed ( $n=66,51.6 \%$ vs $n=62,48.4 \%$, respectively). Additionally, most of the participants $(n=114,89.1 \%)$ were not aware of the lesions. Regarding para-habits, $36.5 \%$ of the participants were current betel users, while $53.9 \%$ were current smokers. 
Table 1

Demographic variables and histopathology diagnosis using TNOMSP

\begin{tabular}{|c|c|c|c|}
\hline & \multicolumn{3}{|c|}{ Histopathology } \\
\hline & All & Dysplasia & Others \\
\hline & $\mathrm{n}(\%)$ & $\mathrm{n}(\%)$ & $\mathrm{n}(\%)$ \\
\hline & $n=134$ & $n=70$ & $n=58$ \\
\hline Age (years) & $56.55 \pm 12.93$ & $58.71 \pm 11.77$ & $53.34 \pm 13.7$ \\
\hline \multicolumn{4}{|l|}{ Sex } \\
\hline Female & $16(12.5 \%)$ & $13(18.6 \%)$ & $3(5.2 \%)$ \\
\hline Male & $112(87.5 \%)$ & $57(81.4 \%)$ & $55(94.8 \%)$ \\
\hline \multicolumn{4}{|l|}{ Education } \\
\hline Junior high school & $28(21.9 \%)$ & $20(28.6 \%)$ & $8(13.8 \%)$ \\
\hline Senior high school or above & $100(78.1 \%)$ & $50(71.4 \%)$ & $50(86.2 \%)$ \\
\hline \multicolumn{4}{|l|}{ Residing } \\
\hline Capital & $66(51.6 \%)$ & $33(47.1 \%)$ & $33(56.9 \%)$ \\
\hline Others & $62(48.4 \%)$ & $37(52.9 \%)$ & $25(43.1 \%)$ \\
\hline \multicolumn{4}{|l|}{ Self-Awareness } \\
\hline No & $114(85.1 \%)$ & $63(90.0 \%)$ & $51(87.9 \%)$ \\
\hline Yes & $14(10.9 \%)$ & $7(10.0 \%)$ & $7(12.1 \%)$ \\
\hline \multicolumn{4}{|l|}{ Betel History } \\
\hline Never or ex-users & $81(63.3 \%)$ & $39(55.7 \%)$ & $42(72.4 \%)$ \\
\hline Current users & $47(36.7 \%)$ & $31(44.3 \%)$ & $16(27.6 \%)$ \\
\hline \multicolumn{4}{|l|}{ Tobacco History } \\
\hline Never or ex-users & $59(46.1 \%)$ & $27(38.6 \%)$ & $32(55.2 \%)$ \\
\hline Current smokers & $69(53.9 \%)$ & $43(61.4 \%)$ & $26(44.8 \%)$ \\
\hline
\end{tabular}

\section{Dysplasia in histopathological examinations}

The histopathological diagnosis of dysplasia according to the socioeconomic characteristics is shown in Table 1 . Of the total 128 participants, 70 were histopathologically diagnosed with dysplasia, and 58 were diagnosed with others, which were more likely to be benign. The mean age of participants with dysplasia 
( $58.71 \pm 11.77$ years) was higher than that of the others ( $53.34 \pm 13.7$ years). In addition, men were predominant in both the dysplasia and others group (81.4\% vs $94.8 \%)$. The proportion of dysplasia and others was evenly distributed among those living in the capital. Regarding self-awareness, $90 \%$ of the participants with dysplasia and $87.9 \%$ of those with others were not aware of the lesion. For the parahabits, more participants diagnosed as others were never or ex-users for betel and tobacco $(72.4 \%$ and $55.2 \%)$, and more participants diagnosed with dysplasia were current users of betel and tobacco (44.3\% and $61.4 \%)$.

\section{Distribution of OPMDs and lesion sites}

The results of COE are listed in Figure 3. Among the 134 subjects, the predominant diagnosis was others, which was likely to be benign, and among all OPMDs, erythroleucoplakia was the most common (23/134, $17.2 \%)$, followed by thin homogeneous leucoplakia (21/134, 15.7\%), and suspected oral cancer (10/134, $7.5 \%)$. Regarding the distribution of lesion sites, most of the lesions were located on the buccal mucosa (61/134, 45.5\%), mandibular gingiva (16/134, 11.9\%), and tongue (13/134, 9.7\%).

\section{Association between severity of dysplasia and socioeconomic status}

Results of the correlation between dysplasia and socioeconomic status are presented in Table 2. We noted a significant correlation between junior high school educational status and moderate/high-grade dysplasia $(P<0.001)$. Lack of awareness was significantly associated with both mild and moderate/highgrade dysplasia $(P=0.002)$. Regarding para-habits, current betel $(P<0.001)$ and tobacco use $(P=0.003)$ were strongly correlated with moderate/high-grade dysplasia. 
Table 2

Association of demographic variables with the severity of OED

\begin{tabular}{|c|c|c|c|}
\hline & \multicolumn{2}{|l|}{ Dysplasia } & \multirow[t]{2}{*}{ P-Value } \\
\hline & Mild & Moderate/High & \\
\hline & n (\%) & $n(\%)$ & \\
\hline & $n=49$ & $n=21$ & \\
\hline Age (years) & $58.61 \pm 11.52$ & $58.94 \pm 12.62$ & 0.915 \\
\hline Sex & & & 0.406 \\
\hline Female & $10(20.4 \%)$ & $3(14.3 \%)$ & \\
\hline Male & $39(79.6 \%)$ & $18(85.7 \%)$ & \\
\hline Education & & & $<0.001$ \\
\hline Junior high school & $3(6.1 \%)$ & $17(81 \%)$ & \\
\hline Senior high school or above & $46(93.9 \%)$ & $4(19 \%)$ & \\
\hline Residing & & & 0.233 \\
\hline Capital & $25(51 \%)$ & $8(38.1 \%)$ & \\
\hline Others & $24(49 \%)$ & $13(61.9 \%)$ & \\
\hline Self-Awareness & & & 0.002 \\
\hline No & 48 (98\%) & $15(71.4 \%)$ & \\
\hline Yes & $1(2 \%)$ & $6(28.6 \%)$ & \\
\hline Betel History & & & $<0.001$ \\
\hline Never or ex-used & $36(73.5 \%)$ & $3(14.3 \%)$ & \\
\hline Current users & $13(26.5 \%)$ & $18(85.7 \%)$ & \\
\hline Tobacco History & & & 0.003 \\
\hline Never smoked & $25(51.0 \%)$ & $2(9.5 \%)$ & \\
\hline Current smokers & $24(48.9 \%)$ & $19(90.5 \%)$ & \\
\hline
\end{tabular}

\section{ORs of the association between severity of dysplasia and socioeconomic status}


Junior high school educational status had a high OR of 1, while senior high school or above educational status had an OR of $0.03(95 \% \mathrm{Cl}: 0.01-0.15 ; P<0.001)$. The current betel users had a high OR of 6.57 (95\% Cl: 1.17-37.0, $P=0.033$ ) (Table 3).

Table 3

\begin{tabular}{|c|c|c|c|}
\hline \multirow[t]{2}{*}{ Characteristic } & \multicolumn{3}{|c|}{ Mild dysplasia vs moderate/high dysplasia } \\
\hline & Odds ratio & $95 \% \mathrm{Cl}$ & P-value \\
\hline \multicolumn{4}{|l|}{ Education } \\
\hline Junior high school & 1 & - & - \\
\hline Senior high school or above & 0.03 & $0.01-0.15$ & $<0.001$ \\
\hline \multicolumn{4}{|l|}{ Betel History } \\
\hline Never or ex-users & 1 & - & - \\
\hline Current users & 6.57 & $1.17-37.0$ & 0.033 \\
\hline
\end{tabular}

\section{Discussion}

Several studies have demonstrated that socioeconomic status influences the development of OPMDs and OED, and the higher the socioeconomic status, the lower the risk of these conditions [13, 19-22]. A large population survey conducted in Taiwan showed a strong correlation between low education status and betel nut use habits, which may be explained by the labouring work in Taiwan that has a cultural tradition of betel nut chewing. Moreover, the Taiwan study revealed that $25 \%$ of individuals with junior high school status were current betel chewers $[23,24]$ This finding is similar to our result of overall dysplasia as we also showed that junior high school education status and current betel chewing were associated with a high risk of OED. Another study in Taiwan reported a 16.5\% prevalence of OED among betel quid chewers [25] Additionally, a hospital-based study revealed an OR of 8.5 (95\% Cl: 4.4-16.2) for the development of oral malignancy among current betel quid chewers with low education status [11]. Moreover, another study in Taiwan revealed an OR of 1.27 (OR=1.27, 95\% Cl: $0.93-1.75)$ for the development of OED among current betel chewers compared with non-chewers [26]. Furthermore, a casecontrol study reported an adjusted OR of 17.43 (95\% Cl: 1.94-156.27) for the occurrence of leucoplakia due to betel nut chewing and smoking [12]. All of the above studies raised concerns about the increasing risk of malignant transformation in current betel chewers. Our present study also showed a high risk of developing moderate/high-grade dysplasia among those in the high-risk group (low educational status and current betel chewing). 
Initiated in 1985, TNOMSP gradually scaled up to the national level and targeted the high-risk group [16]. High-risk individuals may be defined as tobacco users and betel chewers [27-29]. Approximately $90 \%$ of mortality resulting from oral malignancy in Southeast Asia occurs among individuals with para-habits, underscoring the need for efficient resource allocation to the high-risk group.[30] Moreover, oral cancer is one of the leading causes of death in adolescent males in Taiwan, with the overall 5-year survival rates for I-IV stages of oral cancer reducing from $70-10 \%$ [31]. Therefore, early prevention and correct diagnosis of OPMDs are needed to improve the patients' outcomes.

Most OPMDs are asymptomatic and are rarely noticed by the patients, which is also evident in our present study as $85.1 \%$ of the participants were not aware of the lesion. The global prevalence of OPMDs is approximately $4.47 \%$ and is considered to be higher among Asian males [32]. Male predominance was also observed in our study. OPMDs mainly occur on the buccal mucosa, gingiva, tongue, and floor of the mouth [33-35]. Similar findings were reported in this study, with a majority of the lesions occurring on the buccal mucosa, followed by mandibular gingiva and tongue. Our study findings are also comparable to those of a recent large population-based study conducted in southern Taiwan [34]. Regarding the type of OPMDs in our study, erythroleucoplakia (17.2\%) was the most common, followed by thin homogeneous leucoplakia (15.7\%). When all types of leucoplakia, including non-homogeneous, thick, and thin homogenous leucoplakia, were included in the same group, the prevalence was $24.6 \%$, and this finding is comparable to that of another large population study conducted in Taiwan [35].

Histopathological diagnosis is necessary for clinical staging of early pathologic changes in OED and helps evaluate the potential for malignant transformation. The OED malignancy transformation rate varies from $0.13-34.30 \%[36,34,37]$. The standard grading system of OED, according to the World Health Organization guidelines, is mild, moderate, and high [38]. For high-grade dysplasia, the transformation rate varies from 7-50\% [39]. In contrast, moderate dysplasia has a malignant transformation potential of $3-15 \%$, whereas mild epithelial dysplasia has a low-risk potential $(<5 \%)[40,41]$. However, due to the subjective grading of dysplasia, a binary grading system is encouraged following pathological research $[42,8,38]$. In our present study, we categorised our cases into mild or moderate/high-grade dysplasia based on our current practices. Individuals with moderate/high-grade dysplasia undergo surgical excision of the lesions, which is consistent with the results of a previous meta-analysis [43]. For mild dysplasia, a follow-up system is recommended, and the patient can undergo less invasive interventions, including cryotherapy, chemoprevention, and photodynamic therapy, which have shown promising results in preventing the malignant transformation of OED $[44,45]$.

The major strength of this study is that it was based on the current setting of oral mucosal screening designed by the Taiwan government as TNOMSP. In addition, screening for OPMD in high-risk individuals was performed by a certified clinical practitioner. However, this study had several limitations. First, TNOMSP focuses on the high-risk individuals aged 20 years and above; thus, the underage individuals with para-habits need further investigation. Second, the principle design of TNOMSP excludes the general population with oral mucosal lesions. Therefore, a large-scale investigation and comparison of individuals with para-habits and the general population should be considered in future research. 


\section{Conclusions}

In our study, we reported a high correlation between severe dysplasia and low education status and current betel use. The socioeconomic status, poor self-awareness, and para-habits history of the patients with OED should be evaluated to identify high-risk individuals. This retrospective study lays the foundation for further investigation of the socioeconomic status and para-habits associated with OED in different regions across Taiwan with a larger population, as well as the evaluation of the efficacy of TNOMSP.

\section{Abbreviations}

Cl: Confidence interval

NDMC: National Defense Medical Center

OED: Oral epithelial dysplasia

OMPD: Oral potentially malignant disorder

OR: Odds ratio

TNOMSP: Taiwanese Nationwide Oral Mucosal Screening Program

TSGH: Tri-Service General Hospital

\section{Declarations}

\section{Ethical approval and consent to participate}

All procedures performed in studies involving human participants were in accordance with the ethical standards of the institutional research committee and with the 1964 Helsinki declaration and its later amendments or comparable ethical standards. This study was approved by the Institutional Review Board of TSGH (approval no. 1-107-05-010). Informed consent was obtained from all individual participants included in the study.

\section{Consent to publish}

Consent to the publication of the image material is given

\section{Availability of data and materials}

The data and materials collected in this research are available from the corresponding author when requested reasonably. 
The authors declare that they have no conflict of interest.

\section{Funding}

This work was supported by the Tri-Service General Hospital, Taiwan, Republic of China (grant nos. TSGH-C05-110035 and TSGH-D-110154), Ministry of National Defense, Republic of China (grant no. MND-MAB-110-076 and MND-MAB-110-043).

\section{Authors contributions}

TEC contributed to conception and design, data analyses, and interpretation, and drafted the manuscript. YCL contributed to histopathology interpretation. CTW contributed to data acquisition, critically revised the manuscript, and gave final approval. STW critically revised the manuscript and gave final approval. YWC critically revised the manuscript and gave final approval. All authors have read and approved the manuscript.

Sheng-Tang Wu and Yuan-Wu Chen have contributed equally to this work

\section{Acknowledgments}

Not applicable.

\section{References}

1. Dost F, Le Cao K, Ford PJ, Ades C, Farah CS. Malignant transformation of oral epithelial dysplasia: a real-world evaluation of histopathologic grading. Oral Surg Oral Med Oral Pathol Oral Radiol. 2014;117:343-52.

2. Arnaoutakis D, Bishop J, Westra W, Califano JA. Recurrence patterns and management of oral cavity premalignant lesions. Oral Oncol. 2013;49:814-7.

3. Kuribayashi Y, Tsushima F, Morita KI, Matsumoto K, Sakurai J, Uesugi A, et al. Long-term outcome of non-surgical treatment in patients with oral leukoplakia. Oral Oncol. 2015;51:1020-5.

4. Pitiyage G, Tilakaratne WM, Tavassoli $M$, Warnakulasuriya S. Molecular markers in oral epithelial dysplasia: review. J Oral Pathol Med. 2009;38:737-52.

5. Banoczy J, Sugar L. Longitudinal studies in oral leukoplakias. J Oral Pathol. 1972;1:265-72.

6. Thomas V, Rema Devi S, Jeyaseelan V,Jeyseelan L. Mucosal disorders with oral epithelial dysplasia risk--development of a simple screening tool for general health care setting. Oral Oncol. 2012;48:6717.

7. Warnakulasuriya S, Johnson NW, van der Waal I. Nomenclature and classification of potentially malignant disorders of the oral mucosa. J Oral Pathol Med. 2007;36:575-80.

8. Warnakulasuriya S. Clinical features and presentation of oral potentially malignant disorders. Oral Surg Oral Med Oral Pathol Oral Radiol. 2018;125:582-90. 
9. Rajaraman P, Anderson BO, Basu P, Belinson JL, D'Cruz A, Dhillon PK, et al. Recommendations for screening and early detection of common cancers in India. Lancet Oncol. 2015;16:e352-61.

10. IARC Working Group on the Evaluation of Carcinogenic Risks to Humans: Human Immunodeficiency Viruses and Human T-Cell Lymphotropic Viruses. Lyon, France, 1-18 June 1996. IARC Monogr Eval Carcinog Risks Hum 1996;67:1-424.

11. Ko YC, Huang YL, Lee $C H$, Chen MJ, Lin LM, Tsai CC. Betel quid chewing, cigarette smoking and alcohol consumption related to oral cancer in Taiwan. J Oral Pathol Med. 1995;24:450-3.

12. Shiu MN, Chen TH, Chang SH, Hahn LJ. Risk factors for leukoplakia and malignant transformation to oral carcinoma: a leukoplakia cohort in Taiwan. Br J Cancer. 2000;82:1871-4.

13. Warnakulasuriya S. Significant oral cancer risk associated with low socioeconomic status. Evid Based Dent. 2009;10:4-5.

14. Petti S, Masood M, Scully C. The magnitude of tobacco smoking-betel quid chewing-alcohol drinking interaction effect on oral cancer in South-East Asia. A meta-analysis of observational studies. PLoS ONE. 2013;8:e78999.

15. Mahalaha SA, Cheruvu VK, Smyth KA. Oral cancer screening: practices, knowledge, and opinions of dentists working in Ohio nursing homes. Spec Care Dentist. 2009;29:237-43.

16. Kao SY, Chu YW, Chen YW, Liu TY. Detection and screening of oral cancer and pre-cancerous lesions. J Chin Med Assoc. 2009;72:227-33.

17. Chen YK, Huang HC, Lin LM, Lin CC. Primary oral squamous cell carcinoma: an analysis of 703 cases in southern Taiwan. Oral Oncol. 1999;35:173-9.

18. Lo WL, Kao SY, Chi LY, Wong YK, Chang RC. Outcomes of oral squamous cell carcinoma in Taiwan after surgical therapy: factors affecting survival. J Oral Maxillofac Surg. 2003;61:751-8.

19. Hashibe M, Jacob BJ, Thomas G,Ramadas K, Mathew B, Sankaranarayanan R, et al. Socioeconomic status, lifestyle factors and oral premalignant lesions. Oral Oncol. 2003;39:664-71.

20. Conway DI, Petticrew M, Marlborough H, Berthiller J, Hashibe M, Macpherson LM. Socioeconomic inequalities and oral cancer risk: a systematic review and meta-analysis of case-control studies. Int $\mathrm{J}$ Cancer. 2008;122:2811-19.

21. Lee $\mathrm{CH}$, Ko AM, Warnakulasuriya S, Ling TY, Rajapakse PS, Zain RB, et al. Population burden of betel quid abuse and its relation to oral premalignant disorders in South, Southeast, and East Asia: an Asian Betel-quid Consortium Study. Am J Public Health 2012;102:e17-24.

22. Huang YT, Ho PS, Jou YY, Wu CY, Wang YW, Yang YH. Determining high prevalence of betel-quid chewing and cigarette smoking by occupation using the Taiwan National Health Interview Survey. Subst Use Misuse. 2020;55:1472-82.

23. Ko YC, Chiang TA, Chang SJ, Hsieh SF. Prevalence of betel quid chewing habit in Taiwan and related sociodemographic factors. J Oral Pathol Med. 1992;21:261-4.

24. Wen CP, Tsai SP, Cheng TY, Chen CJ, Levy DT, Yang HJ, et al. Uncovering the relation between betel quid chewing and cigarette smoking in Taiwan. Tob Control. 2005;14:i16-22. 
25. Lee $\mathrm{CH}$, Ko AM, Warnakulasuriya S, Yin BL, Zain RB, Ibrahim SO, et al. Intercountry prevalences and practices of betel-quid use in south, southeast and eastern Asia regions and associated oral preneoplastic disorders: an international collaborative study by Asian betel-quid consortium of south and east Asia. Int J Cancer. 2011;129:1741-51.

26. Lee JJ, Hung HC, Cheng SJ, Chen YJ, Chiang CP, Liu BY, et al. Carcinoma and dysplasia in oral leukoplakias in Taiwan: prevalence and risk factors. Oral Surg Oral Med Oral Pathol Oral Radiol Endod. 2006;101:472-80.

27. Lu Y, Sobue T, Kitamura T, Matsuse R, Kitamura Y, Matsuo K, et al. Cigarette smoking, alcohol drinking, and oral cavity and pharyngeal cancer in the Japanese: a population-based cohort study in Japan. Eur J Cancer Prev. 2018;27:171-9.

28. Shiu MN, Chen TH. Impact of betel quid, tobacco and alcohol on three-stage disease natural history of oral leukoplakia and cancer: implication for prevention of oral cancer. Eur $\mathrm{J}$ Cancer Prev. 2004;13:39-45.

29. Sankaranarayanan R, Mathew B, Jacob BJ, Thomas G, Somanathan T, Pisani P, et al. Early findings from a community-based, cluster-randomized, controlled oral cancer screening trial in Kerala, India. The Trivandrum Oral Cancer Screening Study Group. Cancer. 2000;88:664-73.

30. Vigneswaran N, Williams MD. Epidemiologic trends in head and neck cancer and aids in diagnosis. Oral Maxillofac Surg Clin North Am. 2014;26:123-41.

31. Tsai KY, Su CC, Chiang CT, Tseng YT, Lian IB. Environmental heavy metal as a potential risk factor for the progression of oral potentially malignant disorders in central Taiwan. Cancer Epidemiol. 2017;47:118-24.

32. Mello FW, Miguel AF, Dutra KL, Porporatti AL, Warnakulasuriya S, Guerra EN, et al. Prevalence of oral potentially malignant disorders: a systematic review and meta-analysis. $\mathrm{J}$ Oral Pathol Med. 2018;47:633-40.

33. Napier SS, Speight PM. Natural history of potentially malignant oral lesions and conditions: an overview of the literature. J Oral Pathol Med. 2008;37:1-10.

34. Wang YY, Tail YH, Wang WC, Chen CY, Kao YH, Chen YK, et al. Malignant transformation in 5071 southern Taiwanese patients with potentially malignant oral mucosal disorders. BMC Oral Health. 2014;14:99.

35. Chung $\mathrm{CH}$, Yang $\mathrm{YH}$, Wang TY, Shieh TY, Warnakulasuriya S. Oral precancerous disorders associated with areca quid chewing, smoking, and alcohol drinking in southern Taiwan. J Oral Pathol Med. 2005;34:460-6.

36. Liu W, Bao ZX, Shi LJ, Tang GY, Zhou ZT. Malignant transformation of oral epithelial dysplasia: clinicopathological risk factors and outcome analysis in a retrospective cohort of 138 cases. Histopathology. 2011;59:733-40.

37. Warnakulasuriya S, Ariyawardana A. Malignant transformation of oral leukoplakia: a systematic review of observational studies. J Oral Pathol Med. 2016;45:155-66. 
38. Ranganathan K, Kavitha L. Oral epithelial dysplasia: classifications and clinical relevance in risk assessment of oral potentially malignant disorders. J Oral Maxillofac Pathol. 2019;23:19-27.

39. Speight PM. Update on oral epithelial dysplasia and progression to cancer. Head Neck Pathol. 2007;1:61-6.

40. Farini R, Pagnini CA, Farinati F, Di Mario F, Cardin F, Vianello F, et al. Is mild gastric epithelial dysplasia an indication for follow-up? J Clin Gastroenterol. 1983;5:307-10.

41. Warnakulasuriya S, Tilakaratne WM, Ranganathan K, Kuriakose MA. Report of a consensus meeting of a group of oral and general pathologists in India on grading of oral epithelial dysplasia. Oral Oncol. 2018;81:109-10.

42. Kujan O, Oliver RJ, Khattab A, Roberts SA, Thakker N, Sloan P. Evaluation of a new binary system of grading oral epithelial dysplasia for prediction of malignant transformation. Oral Oncol. 2006;42:98793.

43. Mehanna HM, Rattay T, Smith J, McConkey CC. Treatment and follow-up of oral dysplasia - a systematic review and meta-analysis. Head Neck. 2009;31:1600-9.

44. Chau L, Jabara JT, Lai W, Svider PF, Warner BM, Lin HS, et al. Topical agents for oral cancer chemoprevention: A systematic review of the literature. Oral Oncol. 2017;67:153-9.

45. Kawczyk-Krupka A, Waskowska J, Raczkowska-Siostrzonek A, Kościarz-Grzesiok A, Kwiatek S, Straszak D, et al. Comparison of cryotherapy and photodynamic therapy in treatment of oral leukoplakia. Photodiagnosis Photodyn Ther. 2012;9:148-55.

\section{Figures}

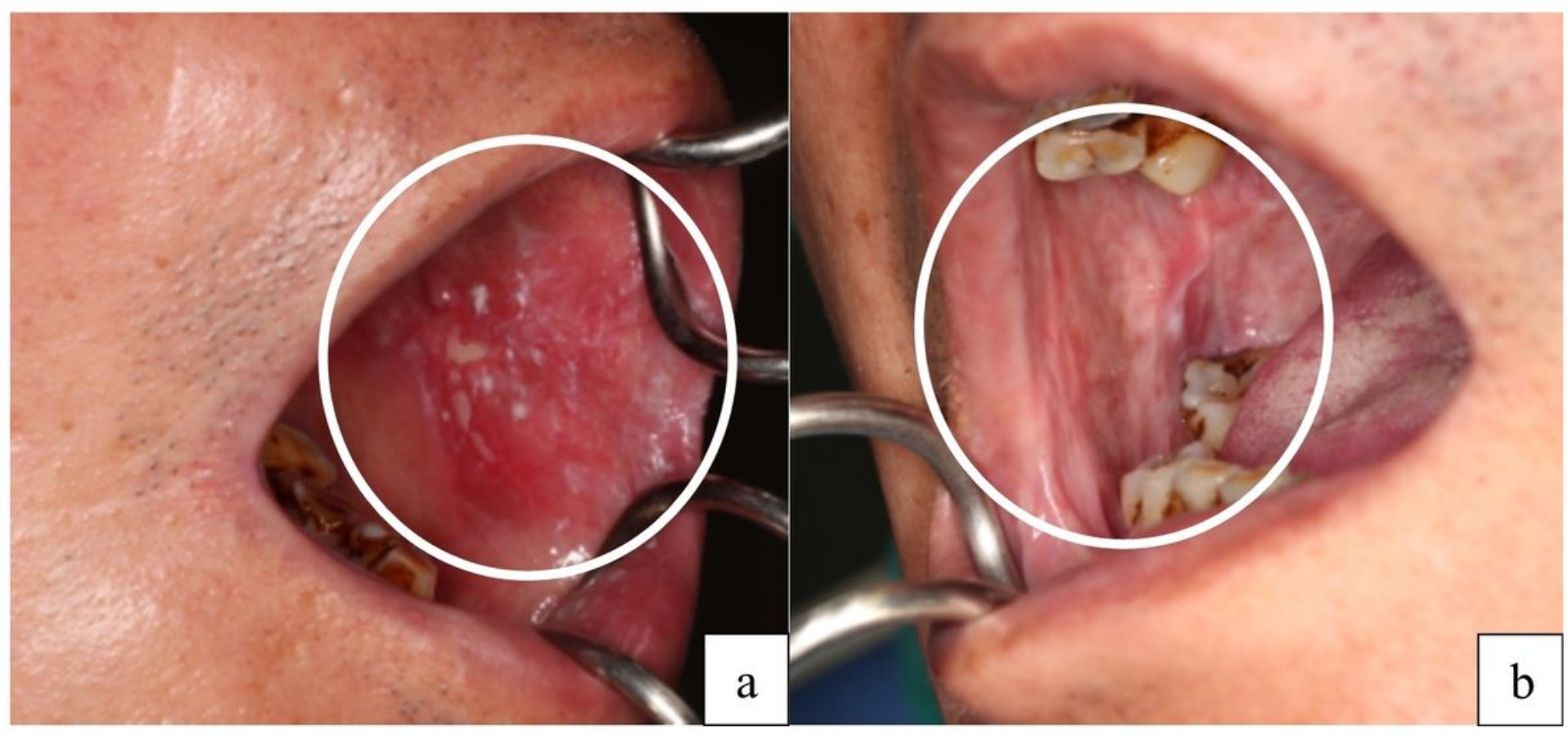


Study participants recruited from TNOMSP study with Para-habits of Tobacco or Betel use. (a) OPMDs diagnosis: Left buccal erythroleucoplakia with current Betel chewing (Noted dental attrition and staining). (b) OPMDs diagnosis: Oral Submucous fibrosis with current Betel chewing (Noted dental attrition and staining). OPMD: Oral potentially malignant disorders, TNOMSP: Taiwanese Nationwide Oral Mucosal Screening Program

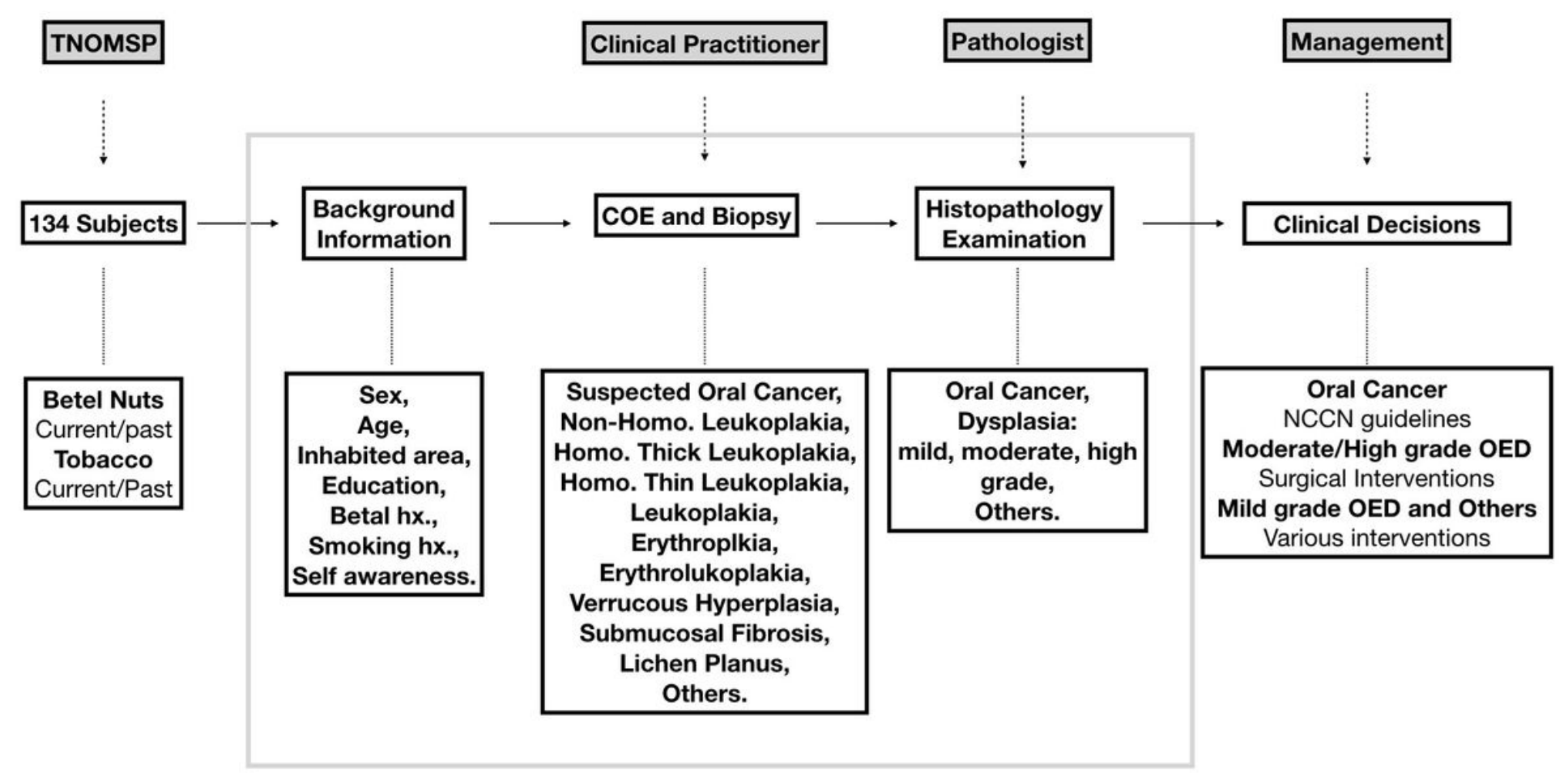

Figure 2

Subjects selected during the clinical examination procedure of TNOMSP 

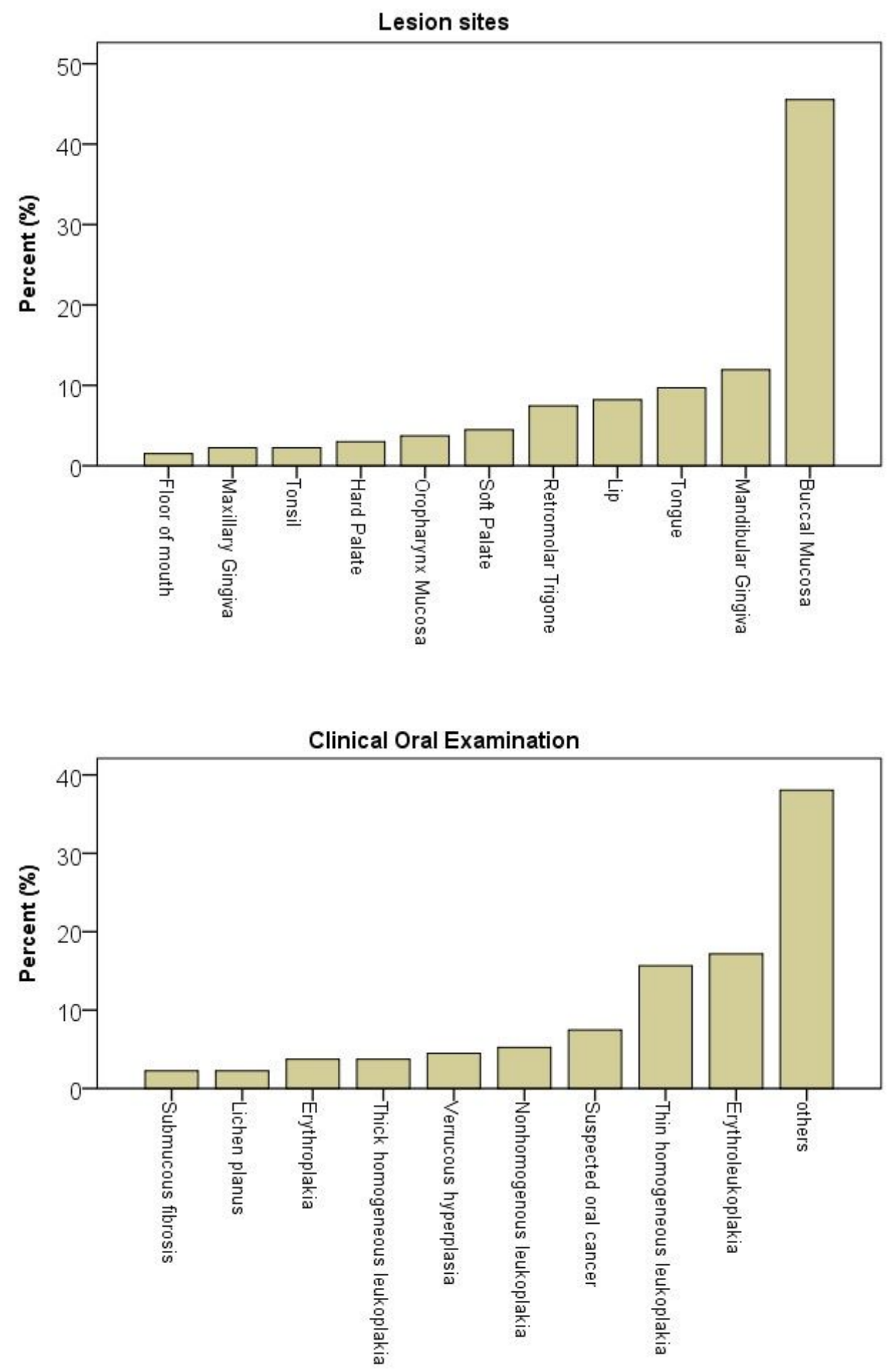

Figure 3

Distribution of clinical characteristics of OPMDs and lesion sites OPMD: Oral potentially malignant disorder 